\title{
Epidural catheterization with a subcutaneous injection port for the long-term administration of opioids and local anesthetics to treat zoster-associated pain
} -a report of two cases -

\author{
Bo Mi Min and Jong Hae Kim \\ Department of Anesthesiology and Pain Medicine, School of Medicine, Catholic University of Daegu, Daegu, Korea
}

Continuous epidural analgesia has been used for decades to treat acute herpes zoster pain and to prevent postherpetic neuralgia. However, many technical problems can arise during chronic treatment with epidural medications. These complications include catheter dislodgement, infection, injection pain, leakage, and occlusion. Epidural catheter placement utilizing subcutaneous injection port implantation has gained widespread acceptance as a method to overcome such complications. The technique reduces the risk of infection, the most feared complication, compared to the use of a percutaneous epidural catheter. Herein, we present 2 cases in which the continuous thoracic epidural administration of opioids and local anesthetics through an implantable subcutaneous injection port for over 2 months successfully treated zosterassociated pain without any technique- or medication-related complications in patients with risk factors for epidural abscess. (Korean J Anesthesiol 2013; 65: 462-467)

Key Words: Epidural injections, Herpes zoster, Local anesthetics, Opioid analgesics.

Continuous epidural analgesia has been used to treat zosterassociated pain for decades [1]. However, technical problems related to the use of percutaneous epidural catheters, such as catheter dislodgement, infection, pain during injection, leakage, and occlusion, make the long-term epidural administration of drugs unacceptable. Among these complications, infection is the most feared [2]. An alternative technique, the implantation of a subcutaneous injection port connected to an epidural catheter, is available as a means of overcoming the complications associ- ated with epidural catheters. The technique can be used in patients who have predisposing factors for epidural abscess, such as diabetes mellitus [2], a history of drug abuse [3], steroid or other immunosuppressive therapy use, malignancy, human immunodeficiency virus infection, alcoholism, and cirrhosis. Using this technique, we were successful in the long-term epidural administration of opioids and local anesthetics to treat zosterassociated pain without any complications arising in patients with predisposing factors for epidural infection.

Received: July 23, 2012. Revised: September 10, 2012. Accepted: September 24, 2012.

Corresponding author: Jong Hae Kim, M.D., Department of Anesthesiology and Pain Medicine, School of Medicine, Catholic University of Daegu, 3056-6, Daemyeong 4-dong, Nam-gu, Daegu 705-718, Korea. Tel: 82-53-650-4979, Fax: 82-53-650-4517, E-mail: usmed@cu.ac.kr () This is an open-access article distributed under the terms of the Creative Commons Attribution Non-Commercial License (http:// creativecommons.org/licenses/by-nc/3.0/), which permits unrestricted non-commercial use, distribution, and reproduction in any medium, provided the original work is properly cited. 


\section{Case Reports}

\section{Case 1}

A 72-year-old man (height $163 \mathrm{~cm}$, weight $72 \mathrm{~kg}$ ) with a 10year history of diabetes mellitus presented with intermittent intolerable sharp and lancinating pain over the left anterior chest wall and the back for 1 month. He received $300 \mathrm{mg} /$ day of carbamazepine, $300 \mathrm{mg} /$ day of gabapentin, and $1500 \mathrm{mg} /$ day of valacyclovir orally for 7 days following diagnosis with acute herpes zoster at a local private clinic. He reported severe pain in the affected area (a score of 8 or 9 on a visual analog scale where 0 indicated "no pain" and 10 indicated "the strongest pain imaginable") despite a healed skin rash. A physical examination revealed allodynia and hyperalgesia over the left T2 and T3 dermatomes. The pain relief was maintained for only 3 days through the use of a thoracic epidural block with $10 \mathrm{ml}$ of $0.1 \%$ bupivacaine and $10 \mathrm{mg}$ of triamcinolone at the intervertebral space between the T1 and T2 (a visual analog scale pain score of 2 or 3). Simultaneously, the gabapentin and carbamazepine dosages were increased to $900 \mathrm{mg} /$ day and $400 \mathrm{mg} /$ day, respectively, and the antiviral therapy was completed. The patient received 6 subsequent blocks, but each block relieved the pain for only 3 days. He complained about the short-lasting effect of the blocks and the frequent follow up. After reviewing the benefit-risk ratio of the various available forms of therapy, the decision was made to implant a subcutaneous port connected to an epidural catheter for the continuous infusion of opioids and local anesthetics.

On arrival in the operating room, the arterial pressure, electrocardiogram, and peripheral oxygen saturation $\left(\mathrm{SpO}_{2}\right)$ of the patient were monitored, and venous access was secured. The patient was positioned on an operating table in the lateral decubitus position with the patient's side for the port pocket nondependent. His arms were extended at the shoulders and secured in position away from the surgical field. The skin was prepared, and sterile drapes were applied. The radiographic Carm was then positioned across the thoracic region to provide a cross-table anteroposterior view of the thoracic spine. Using fluoroscopy, the T7-8 interspace, which was thought to be the most appropriate interspace, was identified for the subcutaneous tunneling of an epidural catheter connected to an injection port placed in the right upper quadrant of the abdomen. An epidural catheter was then inserted through an 18-gauge Tuohy needle using a loss of resistance technique until the tip was at the intervertebral space between the T1 and T2 (Fig. 1A). The needle was then withdrawn. An $8 \mathrm{~cm}$ transverse incision was made in the right upper quadrant of the abdomen, and a subcutaneous pocket was created caudad to the incision using a blunt dissection. A tunneling device was then extended within the subcutaneous tissue between the needle insertion site and the pocket. The catheter was then advanced through the tunnel and trimmed to a length that allowed a small loop of catheter to remain deep to the port (Celsite ${ }^{\circledR}$, B. Braun, Boulogne-Billancourt, France). The port was connected to the epidural catheter and sutured to the abdominal fascia. Finally, the skin incision was closed. A port needle (Hubsite ${ }^{\circledR}$, B. Braun, Ecouen, Germany) with a length appropriate for the thickness of the subcutaneous needle was used to deliver epidural medications: $25 \mathrm{mg}$ of morphine, 200 $\mathrm{mg}$ of bupivacaine, and $185 \mathrm{ml}$ of normal saline (a total volume of $250 \mathrm{ml}$ ) (Fig. 1B and 1C). The background infusion rate was 2 $\mathrm{ml} / \mathrm{hr}$ (no bolus).

After the completion of the procedure, the patient was delivered to the general ward and was observed closely for morphine-induced respiratory depression using pulse oximetry.
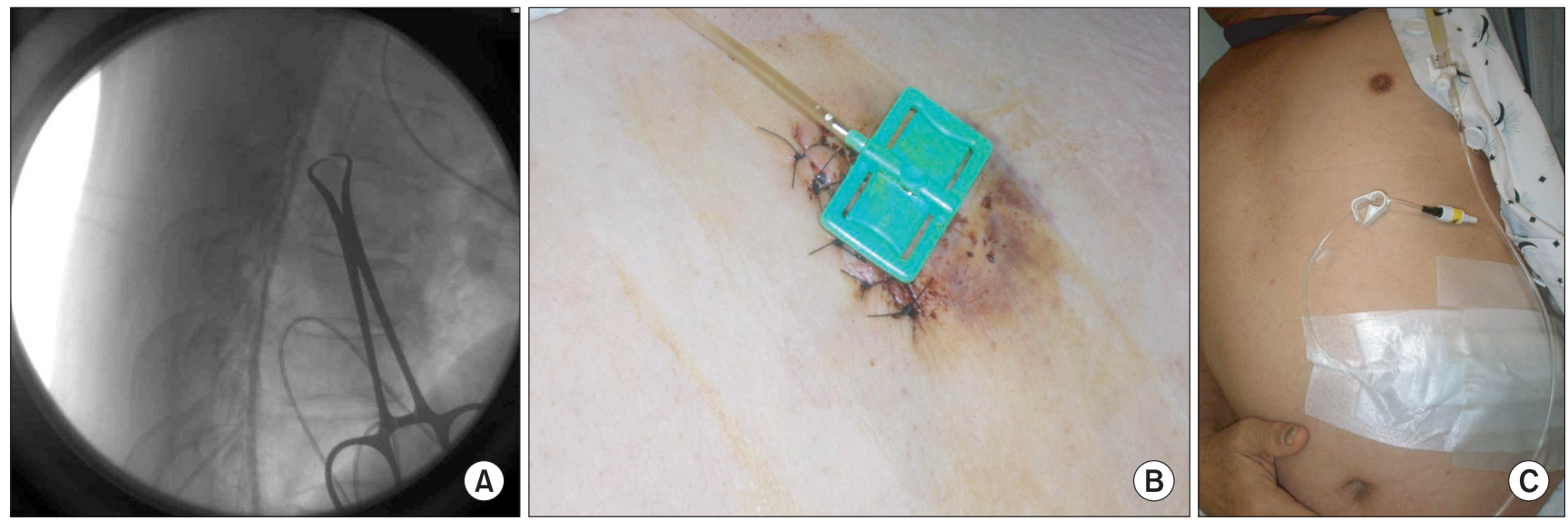

Fig. 1. Epidural catheter placement and the implantation of a subcutaneous injection port. (A) A lateral fluoroscopic view of the thoracic epidural contrast spread after a thoracic interlaminar injection. (B) An infusion device with a Huber bevel (Hubsite ${ }^{\circledR}$, B. Braun, Ecouen, Germany) placed into the port through the skin immediately after the implantation of the subcutaneous injection port (Celsite ${ }^{\circledR}$, B. Braun, Boulogne-Billancourt, France). (C) A dressed infusion device with a Huber bevel connected to an epidural infusion pump (Accufuser ${ }^{\circledR}$, WooYoung Medical, Seoul, Korea). 
The other side effects related to the use of epidural morphine and bupivacaine (pruritus, nausea, vomiting, urinary retention, constipation, systemic toxicity, motor weakness, etc.) were also monitored. Oral bisacodyl (5 mg) and docusate $(16.75 \mathrm{mg})$ were administered daily for constipation prophylaxis. Because no side effects or complications associated with the epidural catheterization, implanted injection port and epidural medications were reported during the 11 days of admission, the patient was discharged and followed up every 10 days to exchange the port needle and epidural infusion pump (Accufuser ${ }^{\circledR}$, WooYoung Medical, Seoul, Korea). The epidural infusion and concurrent administration of $900 \mathrm{mg} /$ day gabapentin and $10 \mathrm{mg} /$ day amitriptyline were maintained for 66 days. During treatment, the patient's pain intensity was successfully reduced from 10 (using the visual analog scale) and maintained between 2 and 3. The patient was very satisfied with the treatment. He reported slight hypoesthesia over the left anterior chest and back in the early treatment period. There were no complications associated with the epidural catheters or the medications used. Sixty-six days after the procedure, the subcutaneous port and epidural catheter were removed due to the obstruction of the catheter. He did not complain of pain thereafter but reported a slight numb sensation that remained over the lesion site for 3 months, during which oral gabapentin and amitriptyline were tapered off uneventfully. The patient was thereafter lost to follow up.

\section{Case 2}

A 64-year-old man (height $160 \mathrm{~cm}$, weight $62 \mathrm{~kg}$ ) with a 10year history of diabetes mellitus, who had undergone a left pneumonectomy due to squamous cell carcinoma in his left upper lobe, presented with pain along the incision site (corresponding to a T5-6 dermatomal distribution) for 20 days. The pain began 3 days before the appearance of vesicles, which appeared 20 days after the pneumonectomy, and a physical examination revealed allodynia and hyperalgesia at the incision site. Following the diagnosis of acute herpes zoster, he was treated with $1000 \mathrm{mg} /$ day of acyclovir intravenously for 5 days and with $150 \mathrm{mg} /$ day of pregabalin orally for 3 weeks. Three weeks after pain onset, he was referred to our department for treatment because the pain persisted after the skin lesions had healed. A thoracic epidural block at the T6 -7 interspace with a single dose of $10 \mathrm{ml}$ of $0.1 \%$ bupivacaine and $10 \mathrm{mg}$ of triamcinolone resulted in complete pain relief and a bilateral sensory block of the T5-8 dermatomes as determined by the pinprick method. However, the pain relief lasted less than 3 days. At this point, he was scheduled to receive 4 cycles of adjuvant chemotherapy. Following the decision that no additional thoracic epidural blocks were possible during the chemotherapy, epidural catheter placement and the subcutaneous implantation of an injection port were recommended. The same procedure as that used in the previous case was performed at the T10-11 interspace with the catheter tip located at the T5 (Fig. 2). Immediately after the completion of the procedure, the epidural infusion device containing $20 \mathrm{mg}$ of morphine, $20 \mathrm{ml}$ of $0.5 \%$ bupivacaine and $210 \mathrm{ml}$ of normal saline (a total volume of $250 \mathrm{ml}$ ) was programmed to deliver at a basal rate of $2 \mathrm{ml} / \mathrm{hr}$ and delivered through a port needle. The side effects and complications associated with the procedure and epidural medications were monitored closely in the general ward. Oral medications consisting of $150 \mathrm{mg} /$ day of pregabalin and $10 \mathrm{mg} /$ day of amitriptyline were maintained. A stool softener and a bowel stimulant were added to the routine medications to prevent opioidinduced constipation. The epidural infusion pump was changed, and the pain intensity was evaluated every 5 days. One week after the procedure was completed, 4 cycles of adjuvant chemotherapy consisting of the daily intravenous administration of paclitaxel $\left(175 \mathrm{mg} / \mathrm{m}^{2} \times 0.9\right)$ and cisplatin $\left(75 \mathrm{mg} / \mathrm{m}^{2} \times 0.9\right)$ began, with 3 weeks between each cycle.
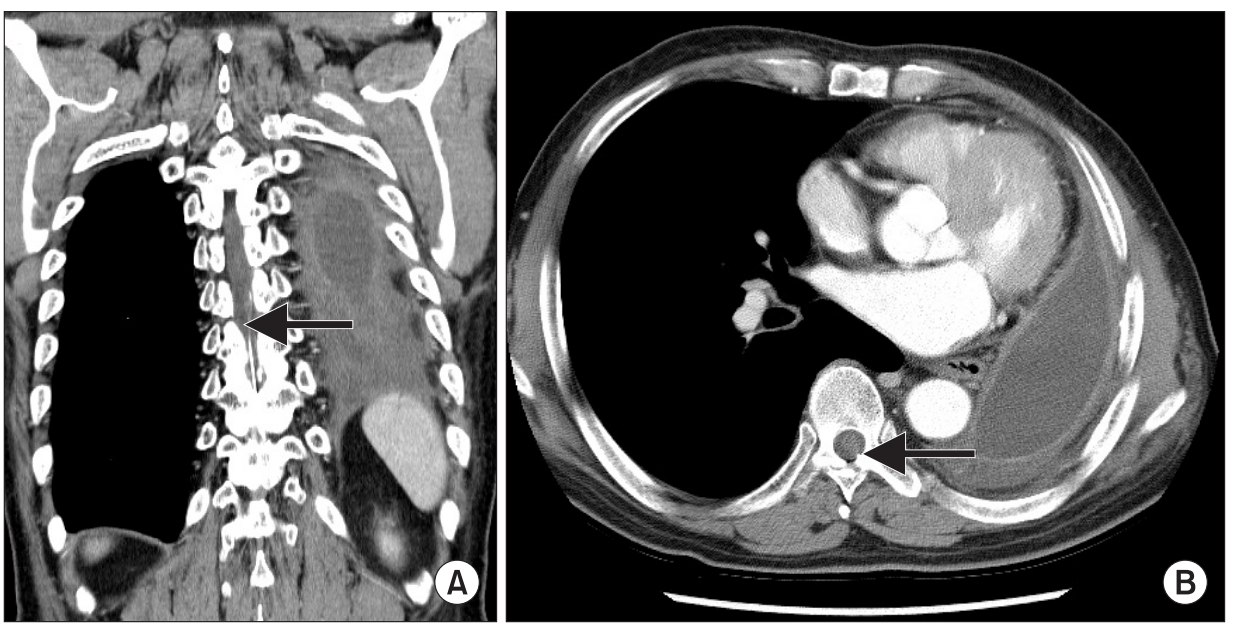

Fig. 2. A coronal section (A) and transverse section (B) of a thoracoabdominal computerized tomography scan 43 days after the placement of the epidural catheter connected to a subcutaneously implanted port. The arrows indicate the correct placement of the epidural catheter in the thoracic epidural space. 
The analgesic regimen decreased the visual analog scale pain score from 8 or 9 to 1 or 2 . The lower pain scores were maintained until the removal of the subcutaneous port and the epidural catheter. Leukocytosis occurred during each chemotherapy cycle, but no epidural catheter infection-associated signs or symptoms presented. During the chemotherapy, no complications related to the subcutaneous port or the epidural catheter were noted. Due to the obstruction of the epidural catheter identified 120 days after the procedure, the catheter and subcutaneous port were removed. After removal, the patient reported a visual analog scale pain score of 1 or 2 . Oral pregabalin and amitriptyline were tapered off uneventfully 1 month after the removal. Although the decreased visual analog pain scores of the zoster-associated pain were maintained during the 6-month follow-up period after the removal, opioid therapy (20 to $80 \mathrm{mg}$ of oxycodone per day) was initiated after a new onset of cancer-related pain (left lower extremity pain). Until his death (16 months after the removal), no symptoms or signs of herpes zoster were reported.

\section{Discussion}

Continuous epidural analgesia through percutaneous epidural catheters, using local anesthetics administered either alone or in combination with steroids, is often used in the management of zoster-associated pain. This treatment method provides profound analgesia with minimal systemic side effects by blocking nociceptive impulses from entering the central nervous system. However, many technical complications are associated with percutaneous epidural catheters, such as catheter dislodgement, infection, injection pain, leakage, and occlusion. Among these complications, epidural infection with subsequent abscess formation and possible spinal cord compression is the most dreaded. Serious systemic infections after short-term (3-5 days) continuous epidural analgesia have been reported [4]. In clinical practice, it is common to remove epidural catheters within 72 hours of insertion to minimize the risk of catheter colonization and systemic infection. However, many patients require analgesia for longer than 72 hours. In these cases, the long-term epidural administration of local anesthetics and opioids using an epidural catheter with a subcutaneous injection port can be used to successfully treat acute phase pain and prevent postherpetic neuralgia without serious local or systemic complications (meningitis, epidural abscess, systemic infection, epidural hematoma, spinal cord injury, local anesthetic toxicity, or opioid-induced side effects).

Percutaneous epidural catheters traverse the integument and interfere with the natural host defenses of the skin. Studies in which epidural catheter tips were cultured following removal demonstrate that epidural catheters are at risk of being con- taminated with skin flora after short-term use [5]. Although the duration that an indwelling epidural catheter can be left in place without risking local or systemic infection is unknown, many reports have shown an increase in the infection rate with time. There is a low incidence of epidural infection with catheterization duration of 2 days or less. Nevertheless, longer durations (more than 5 days) have been associated with a $4.3 \%$ infection incidence [6]. An alternative to a percutaneous epidural catheter is a surgically implanted catheter with a subcutaneous port site for injection. The advantages over percutaneous epidural catheterization include a lower incidence of skin and subcutaneous tissue infections, catheter dislodgement, and kinking [7]. Because the risk of infection increases at a far later stage of treatment than with percutaneous catheters, a relatively longterm administration of epidural drugs is possible. Furthermore, a previous case study reported that an epidural catheter with a subcutaneous port functioned well for more than 31 months [8].

Diabetes mellitus is considered the most important risk factor of spinal epidural abscesses, occurring in $18-54 \%$ of cases [2]. Other risk factors include chronic renal failure, alcoholism, and malignancy [9]. All of these risk factors are associated with compromised immunity. The site of catheter insertion is an additional factor in the development of epidural abscess. Thoracic catheters are associated with a high incidence of epidural abscess [9]. Both patients had at least one of the risk factors, diabetes mellitus, and required thoracic epidural catheterization. In particular, the patient in the second case was diagnosed with lung cancer and received adjuvant chemotherapy, which may have aggravated his compromised immunity. Thus, both patients were predisposed to develop an epidural abscess, and percutaneous epidural catheterization was not suitable for the continuous infusion of medications for more than 2 months. In addition, the immunocompromised state (diabetes mellitus) induced an atypical manifestation, such as the involvement of multiple dermatomes (T2 and T3) in the first case, while only a single dermatome is typically affected in immunocompetent patients.

Steroids reduce deafferentation by inhibiting inflammation and concomitant swelling-induced neural ischemia. Local anesthetics provide analgesia and sympathetic blockade, interrupting the process of sensitization. Consequently, neural damage and the subsequent neuropathic pain are reduced. However, our treatments did not incorporate steroids; previous studies have questioned the efficacy of these drugs and suggested that steroids increase the risk of herpes dissemination [10] and adrenal suppression. Moreover, steroids are the third most important spinal epidural abscess risk factor. In particular, when injected epidurally in chronic pain states, the use of corticosteroids can increase the risk of epidural infection [11]. Therefore, we decided to use local anesthetics without steroids. Previous studies also support our decision, reporting patients who achieved earlier 
pain cessation and a shorter duration of zoster-associated pain following treatment with a continuous epidural infusion of local anesthetics alone through percutaneous epidural catheters for approximately 2 or 3 weeks [1]. We successfully managed zosterassociated pain through the long-term (more than 2 months) epidural infusion of local anesthetics.

A growing body of evidence suggests that opioid analgesics may provide pain relief to patients with postherpetic neuralgia. As a lipophobic opioid, morphine acts by rostral spread from the thoracolumbar epidural space to the cervical and intraventricular cerebrospinal fluid. It produces a potent analgesic effect when administered into the epidural space because it increases the concentration in both the cerebrospinal fluid and plasma. However, the use of the technique is controversial because of the incidence of undesirable side effects, particularly the risk of delayed respiratory depression [12]. Other side effects include pruritus, nausea, vomiting, and urinary retention. Nevertheless, Jain et al. [13] demonstrated that subanesthetic concentrations $(0.0625 \%)$ and doses $(3.2 \mathrm{mg} / \mathrm{hr})$ of bupivacaine with morphine $(0.0075 \%, 0.35 \mathrm{mg} / \mathrm{hr})$ administered epidurally in continuous infusion provide superior postoperative analgesia without side effects in patients undergoing major thoracoabdominal surgery. The superior analgesia without side effects was also achieved in our cases with the use in our patients of $1.6 \mathrm{mg} / \mathrm{hr}$ of $0.08 \%$ bupivacaine accompanied by $0.2 \mathrm{mg} / \mathrm{hr}$ of $0.01 \%$ morphine and $0.8 \mathrm{mg} / \mathrm{hr}$ of $0.04 \%$ bupivacaine with $0.16 \mathrm{mg} / \mathrm{hr}$ of $0.008 \%$ morphine.

In contrast, only a few reports have used epidural morphine to manage zoster-associated pain. Wong et al. [14] reported the successful treatment of postherpetic neuralgia with the epidural administration of $10 \mathrm{mg}$ of ketamine, $1 \mathrm{mg}$ of morphine, and 6 $\mathrm{ml}$ of bupivacaine $(0.1 \%)$, suggesting a synergistic effect from this combination. In a single-blind, placebo-controlled study to assess the effectiveness of epidural morphine in controlling pain in 11 patients with postherpetic neuralgia, Watt et al. [15] reported that only 2 patients obtained a $>50 \%$ reduction in pain. The investigators suggested that epidural morphine is more likely to produce side effects than pain relief when administered to patients with postherpetic neuralgia. Because no prospective, randomized, controlled clinical trials that demonstrate the effectiveness of long-term epidural morphine analgesia for zosterassociated pain are currently available, it is unclear whether epidural morphine controls zoster-associated pain. Nevertheless, epidural morphine appears to play a central role in managing acute phase pain and preventing postherpetic neuralgia without side effects for a lengthy duration in the 2 cases reported herein.

In summary, an epidural catheter with a subcutaneous injection port delivers opioids and local anesthetics effectively for a long duration without any complications in patients suffering from zoster-associated pain. However, the safety and efficacy of the long-term epidural administration of opioids and local anesthetics through an epidural catheter with a subcutaneous port in herpes zoster patients has not been established. Furthermore, the indications for using this therapy are not clear. Therefore, further studies are warranted to verify the effectiveness of epidural catheters with subcutaneous injection ports and to evaluate the effects of the long-term use of epidural opioids and local anesthetics in herpes zoster patients.

\section{References}

1. Manabe H, Dan K, Hirata K, Hori K, Shono S, Tateshi S, et al. Optimum pain relief with continuous epidural infusion of local anesthetics shortens the duration of zoster-associated pain. Clin J Pain 2004; 20: 302-8.

2. Hlavin ML, Kaminski HJ, Ross JS, Ganz E. Spinal epidural abscess: a ten-year perspective. Neurosurgery 1990; 27: 177-84.

3. Van Winter JT, Nielsen SN, Ogburn PL Jr. Epidural abscess associated with intravenous drug abuse in a pregnant patient. Mayo Clin Proc 1991; 66: 1036-9.

4. Knight JW, Cordingley JJ, Palazzo MG. Epidural abscess following epidural steroid and local anaesthetic injection. Anaesthesia 1997; 52: 576-8.

5. Nickels JH, Poulos JG, Chaouki K. Risks of infection from short-term epidural catheter use. Reg Anesth 1989; 14: 88-9.

6. Holt HM, Andersen SS, Andersen O, Gahrn-Hansen B, Siboni K. Infections following epidural catheterization. J Hosp Infect 1995; 30: 253-60.

7. de Jong PC, Kansen PJ. A comparison of epidural catheters with or without subcutaneous injection ports for treatment of cancer pain. Anesth Analg 1994; 78: 94-100.

8. Zadra N, Ambrosio F, Piranese A, Giusti F. Use of the peridural catheter with subcutaneous port in a 13-year-old girl: 120 anesthesia procedures in 31 months. J Pediatr Surg 1995; 30: 1493-4.

9. Okano K, Kondo H, Tsuchiya R, Naruke T, Sato M, Yokoyama R. Spinal epidural abscess associated with epidural catheterization: report of a case and a review of the literature. Jpn J Clin Oncol 1999; 29: 49-52.

10. Wood MJ, Johnson RW, McKendrick MW, Taylor J, Mandal BK, Crooks J. A randomized trial of acyclovir for 7 days or 21 days with and without prednisolone for treatment of acute herpes zoster. N Engl J Med 1994; 330: 896-900.

11. Ranasinghe JS, Lee AJ, Birnbach DJ. Infection associated with central venous or epidural catheters: how to reduce it? Curr Opin Anaesthesiol 2008; 21: 386-90. 
12. London SW. Respiratory depression after single epidural injection of local anesthetic and morphine. Anesth Analg 1987; 66: 797-9.

13. Jain PN, Arora A, Myatra SN, Gehdoo RP. Continuous infusion of epidural morphine and bupivacaine for postoperative pain relief: A prospective study. Indian J Anaesth 2003; 47: 454-5.

14. Wong CS, Shen TT, Liaw WJ, Cherng CH, Ho ST. Epidural coadministration of ketamine, morphine and bupivacaine attenuates postherpetic neuralgia--a case report. Acta Anaesthesiol Sin 1996; 34: 151-5.

15. Watt JW, Wiles JR, Bowsher DR. Epidural morphine for postherpetic neuralgia. Anaesthesia 1996; 51: 647-51. 